\title{
Percepção de mulheres quanto à sua vulnerabilidade às Infecções Sexualmente Transmissiveis ${ }^{a}$
}

\author{
Women's perception of their vulnerability to Sexually Transmitted Infections \\ Percepción de las mujeres de su vulnerabilidad a las Infecciones Sexualmente Transmisibles
}

\begin{abstract}
Samy Loraynn Oliveira Moura ${ }^{1}$ (D) Maria Adelane Monteiro da Silva ${ }^{1}$ (1) Andréa Carvalho Araújo Moreira ${ }^{1}$ (1) Cibelly Aliny Siqueira Lima Freitas ${ }^{1}$ (1)

Ana Karina Bezerra Pinheiro² (1)
\end{abstract}

1. Universidade Estadual Vale do Acaraú,

Sobral, CE, Brasil.

2. Universidade Federal do Ceará, Fortaleza, CE, Brasil.
Autor correspondente:

Samy Loraynn Oliveira Moura.

E-mail: loraynn_25@hotmail.com.

Recebido em 29/11/2019.

Aprovado em 04/07/2020.

DOI:https://doi.org/10.1590/2177-9465-EAN-2019-0325

\section{Resumo}

Objetivo: Analisar a percepção de mulheres quanto à sua vulnerabilidade às infecções sexualmente transmissíveis. Método: Trata-se de um estudo exploratório e descritivo com abordagem qualitativa, desenvolvido entre os meses de agosto de 2018 a outubro de 2019, em uma Unidade Básica de Saúde. Participaram do estudo oito mulheres, na faixa etária de-21 a 44 anos com histórico prévio de infecções sexualmente transmissíveis. Os dados coletados com entrevistas semiestruturadas foram submetidos à análise temática proposta por Bardin. Resultados: Há baixa percepção e desconsideração das mulheres sobre sua condição de vulnerabilidade a essas infecções. Elas acreditam que a possibilidade de adquiri-las está relacionada a comportamentos considerados desviantes, sendo provável na vida de quem não vivencia um relacionamento estável. Conclusão e Implicações para a prática: O principal desafio é superar situações vivenciadas pelas mulheres que potencializam as suas vulnerabilidades geradas por equívocos e erros de concepções. Precisa-se planejar ações de prevenção que não se limitam ao repasse de informações, mas a troca de saberes, crenças e valores vinculados à forma pelo qual a mulher vive sua sexualidade.

Palavras-chave: Vulnerabilidade em Saúde; Infecções Sexualmente Transmissíveis; Mulher; Gênero e Saúde; Saúde Coletiva.

\section{Abstract}

Objective: To analyze the perception of women regarding their vulnerability to sexually transmitted infections. Method: This is an exploratory and descriptive study with a qualitative approach, developed between August 2018 and October 2019, in a Primary Healthcare Unit. Eight women, aged between 21 and 44 years participated in the study with previous history of sexually transmitted infections. The data collected with semi-structured interviews were submitted to thematic analysis proposed by Bardin. Results: There is low perception and disregard by women about their condition of vulnerability to these infections. They believe that the possibility of acquiring them is related to behaviors considered deviant, being likely in the life of those who do not experience a stable relationship. Conclusion and Implications for the practice: The main challenge is to overcome situations experienced by women that enhance their vulnerabilities generated by mistakes and misconceptions. It is necessary to plan preventive actions that are not limited to the transmission of information, but the exchange of knowledge, beliefs and values linked to the way in which women experience their sexuality.

Keywords: Vulnerability in Health; Sexually Transmitted Infections; Woman; Gender and Health; Collective Health.

\section{Resumen}

Objetivo: Analizar la percepción de las mujeres de su vulnerabilidad a las infecciones de transmisión sexual. Método: Trata-se de um estudo exploratório e descritivo com abordagem qualitativa, desenvolvido entre os meses de agosto de 2018 a outubro de 2019, em uma Unidade Básica de Saúde. Participaram do estudo oito mulheres, na faixa etária de-21 a 44 anos e histórico prévio de infecções sexualmente transmissíveis. Os dados coletados com entrevistas semiestruturadas foram submetidos à análise temática proposta por Bardin. Método: Se trata de un estudio exploratorio y descriptivo con enfoque cualitativo, desarrollado entre los meses de agosto de 2018 y octubre de 2019, en una Unidad Básica de Salud. Ocho mujeres en el grupo de edad de 21 a 44 años participaron en el estudio con historia previa de infecciones de transmisión sexual. Los datos recopilados con entrevistas semiestructuradas se sometieron a un análisis temático propuesto por Bardin. Resultados: Hay una baja percepción y desprecio por parte de las mujeres de su vulnerabilidad a estas infecciones. Creen que la posibilidad de adquirirlas está relacionada con comportamientos considerados desviados, siendo probable en la vida de aquellos que no experimentan una relación estable. Conclusión e implicaciones para la práctica: El principal desafío es superar las situaciones experimentadas por las mujeres que aumentan sus vulnerabilidades generadas por errores y conceptos erróneos. Es necesario planificar acciones preventivas que no se limiten a la transmisión de información, sino al intercambio de conocimientos, creencias y valores vinculados a la forma en que las mujeres experimentan su sexualidad.

Palabras clave: Vulnerabilidad en la salud; Infecciones de transmisión sexual; Mujer; Género y salud; Salud pública. 


\section{INTRODUÇÃO}

As Infecções Sexualmente Transmissíveis (IST) estão entre os problemas de saúde pública mais comum em todo o mundo, apesar de todo o avanço científico, tecnológico, preventivo e curativo. Inclui uma série de síndromes clínicas, que pode ser disseminada principalmente por meio do contato sexual. São capazes de tornar o organismo humano mais vulnerável a outras doenças e apresentam complicações mais graves em mulheres, tais como infertilidade, abortamento espontâneo, malformações congênitas e até a morte, caso não sejam tratadas. ${ }^{1,2}$

De acordo com a Organização Mundial de Saúde (OMS), mais de um milhão de pessoas adquirem uma IST diariamente e a cada ano 500 milhões de pessoas adquirem uma das IST curáveis (gonorreia, clamídia, sífilis e tricomoníase), sendo que a sífilis na gravidez causa aproximadamente 300.000 mortes fetais e neonatais/ano e coloca 215.000 recém-nascidos sob o risco de morte prematura, baixo peso ao nascimento ou sífilis congênita; 530 milhões de pessoas estejam infectadas com o vírus do herpes genital e que mais de 290 milhões de mulheres estejam infectadas, pelo Papiloma Vírus Humano (HPV). A infecção pelo HPV causa 530.000 casos de câncer de colo uterino e 275.000 mortes por ano. ${ }^{3,4}$

É notório que o perfil epidemiológico das IST vem se modificando durante as últimas décadas em todo o mundo, com aumento expressivo do número de casos entre mulheres. Os contextos históricos revelam que as mulheres brasileiras enfrentam obstáculos em virtude do preconceito, dos processos vinculados à dinâmica de gênero e das relações sexuais e reprodutivas. $A$ multiplicidade de parceiros sexuais, assimetria nas relações entre mulheres e homens, dogmas religiosos e implicações morais expõem o público feminino às IST e, concomitantemente, acentua a vulnerabilidade das mulheres. ${ }^{5}$

As mulheres são especialmente mais vulneráveis às IST por características biológicas, questões de gênero e social, que impõem a elas condições de submissão e inferioridade em relação aos homens, privando-as, inclusive, do poder de decisão acerca da atividade sexual com proteção; atividade sexual precoce, baixa escolaridade, baixa renda e à dependência econômica das mulheres, especialmente nos países em desenvolvimento. Além disso, existe a falta de percepção da população feminina em contrair uma IST, visto que as mesmas atrelam esse risco em outras mulheres e não em si mesmas. Destaca-se também, que a maioria das mulheres associa o uso do preservativo como forma de evitar uma gravidez não planejada e não como prevenção para esses agravos. ${ }^{6}$

A vulnerabilidade pode ser definida como uma situação resultante de um conjunto de fatores individuais, programáticos, sociais e culturais, interdependentes e mutuamente influenciáveis, relacionados ao grau e modo de exposição a uma dada situação, que acarretam maior suscetibilidade ao adoecimento. Dessa forma, sua definição pode ser aplicada a uma pessoa ou a um grupo social conforme a capacidade de prevenir, de resistir e de contornar potenciais impactos..$^{7,8}$

A vulnerabilidade são processos provenientes do
[...] não reconhecimento, ou desrespeito, com consequências danosas para aqueles que o sofrem, ao mesmo tempo em que expõem fragilidades (afetivas, normativas e éticas) que reclamam respostas que podem se estender do plano das relações interpessoais até o campo macropolítico da conformação das normatividades sociais e estruturações institucionais. 8:22 $^{2}$

O conceito de vulnerabilidade em saúde foi elucidado, partindo de inquietações oriundas da percepção de que o sentido de risco ainda está atrelado aos conceitos pré-existentes e por considerar que elementos essenciais da vulnerabilidade devem ser sustentados pelo sujeito e o social. Assim a autora traz como definição: "[...] uma condição humana, construída na interação entre o sujeito e o social, caracterizada por uma relação de poder que se movimentam direção a uma condição de precariedade quando o empoderamento não é vivenciado pelo sujeito ou coletivo". 9:126 Nessa perspectiva, entende-se que a vulnerabilidade carregue imprecisões frutificadas pelo processo de construção conceitual em que se encontra, há avanços na discussão da realidade dinâmica e multideterminada. É em função dessa compreensão, que a presente pesquisa adota esse conceito de vulnerabilidade, como referencial teórico.

A acepção da vulnerabilidade como parâmetro de reflexão e atuação implica o reconhecimento da concomitância de fatores éticos, políticos e técnicos contornando a incidência de riscos nos territórios e a capacidade humana para o seu enfrentamento. ${ }^{10}$ Portanto, é necessário pensar que cada elemento da vulnerabilidade pode ser adotado como parâmetro para interpretação de vários agravos à saúde. Assim, pode ampliar a atuação em saúde, bem como gerar reflexões e ações de políticas de saúde com base nas necessidades da coletividade.

Mediante a problemática elucidada, considera-se que as vulnerabilidades das mulheres às IST representam um problema importante e que deve ser alvo de ações no âmbito da saúde, pois influencia, sobretudo, na qualidade de vida da população. Julga-se também que as situações de vulnerabilidade podem ser minimizadas para a ocorrência de IST, caso sejam efetivadas ações de prevenção sexuais eficazes e transformadoras que possam desencadear um processo de empoderamento, corresponsabilidade e bem-estar biopsicossocial nas mulheres. Nesse sentido, a pesquisa teve como objetivo analisar a percepção de mulheres quanto a sua vulnerabilidade às Infecções Sexualmente Transmissíveis, partindo da seguinte questão norteadora: qual a percepção que as mulheres têm quanto a sua vulnerabilidade as IST?

Acredita-se que este estudo obterá um importante impacto na saúde das mulheres, pois se espera que subsidie gestores e equipes de saúde no desenvolvimento de estratégias preventiva e clínica de qualidade que contemplem as necessidades desse grupo de forma mais efetiva, integral e participativa, assim, proporcione uma prática profissional sistemática e contextualizada, contribuindo para a atenuação dessa problemática e otimização dos serviços prestados na Atenção Primária à Saúde. É vital a 
busca de novos conhecimentos e alternativas para redução dos problemas existentes na comunidade na qual estamos inseridos.

\section{MÉTODO}

Trata-se de uma pesquisa exploratória e descritiva de natureza qualitativa, que toma como referência o conceito de vulnerabilidade em seu âmbito individual e social, desenvolvida, entre o período de agosto de 2018 a outubro de 2019 , sendo a coleta das informações realizada nos meses de junho e julho de 2019 e a análise das informações obtida de agosto a outubro de 2019. Teve como cenário a UBS Otilha Feitosa da Silva/PSF V por estar situada em um território que apresenta maior índice de casos de IST, conforme a análise da base de dados, do sistema SINAN/NET. ${ }^{11}$

O desenvolvimento dessa pesquisa realizou-se em 3 etapas: 1a Etapa: identificação das mulheres participantes, mediante busca nos prontuários e no livro de registro de exame ginecológico com intuito de identificar as que, conforme os critérios estabelecidos, poderiam participar do estudo. Foram identificadas 26 mulheres; $2^{2}$ Etapa: visita domiciliar, momento em que ocorreu a apresentação da pesquisa e o convite para participação e, conforme aceite, agendada a entrevista. 3 a Etapa: foi aplicado um instrumento de roteiro de entrevista com as mulheres, previamente selecionadas, com o intento de conhecer os contextos de vulnerabilidade.

Participaram da pesquisa oito mulheres na faixa etária de 21 a 44 anos, selecionadas conforme os seguintes critérios de inclusão: mulheres residentes no território da UBS Otilha Feitosa da Silva com faixa etária de 15 a 44 anos (fase reprodutiva), abordadas aleatoriamente, independente do nível de escolaridade, raça e religião; histórico de contaminação por uma IST e capacidade autodeclarada que demonstrasse condições para responder e compreender as perguntas do roteiro de entrevista. A composição da amostra se deu de forma intencional, aleatória e por saturação. Salienta-se que das 26 mulheres selecionadas foram realizadas oito entrevistas, haja vista que a amostra atingiu a saturação e nenhuma delas se recusou a participar da pesquisa.

Amostragem por saturação é utilizada para estabelecer ou fechar o tamanho final de uma amostra em estudo, interrompendo a captação de novos componentes, baseado no fato de que o acréscimo de novas observações não contribui para um aumento significativo de informações e, desse modo, a inclusão de novos participantes, na avaliação do pesquisador, leva à redundância ou à repetição das informações. ${ }^{12}$

As entrevistas foram aplicadas em local reservado, sugerido pelas participantes. Logo, essas aconteceram na UBS, em uma sala fechada, livre de interferências, o que garantiu confidencialidade e ininterrupção ao processo. Tiveram duração de 60 minutos com perguntas mediadas pelo pesquisador responsável, gravadas em aparelho digital com prévia autorização das participantes e, posteriormente, transcritas, o que assegurou dados na integra e a essência das falas.

Tendo em vista a coerência entre os pressupostos teóricos e metodológicos e a maneira mais apropriada de análise dos conteúdos surgidos mediante a aplicação do instrumento, foi adotada como técnica de análise e tratamento das informações, a categorização temática proposta por Bardin, uma modalidade de análise de conteúdo que operacionalmente é constituído por três etapas: a pré-análise, a análise, o tratamento dos resultados e interpretação. ${ }^{13}$

Por tratar-se de uma pesquisa científica envolvendo seres humanos asseguraram-se os princípios éticos e legais postulados na Resolução do Conselho Nacional de Saúde de no 466/12, ${ }^{14}$ sendo aprovada em 08 de junho de 2019, pelo Comitê de Ética em Pesquisa da Universidade Estadual Vale do Acaraú, em Sobral/CE, sob o parecer de nㅇ⒊378.814/ CAEE - 13897819.2.0000.5053. Como garantia da confidencialidade e anonimato, foi utilizada para identificar os participantes da pesquisa à letra "E" seguido de um número arábico (E1, E2, E3, E4, E5, E6, E7, E8...).

\section{RESULTADOS}

Ao analisar as entrevistas, emergiram aspectos sobre a percepção da mulher em relação às vulnerabilidades às IST que as levam a se sentirem protegidas e limitam a sua consideração de vulnerabilidade para realizar ações concretas de prevenção, situações essas que fortalecem as Vulnerabilidades em Saúde. Surgiram elementos comuns que favoreceram a construção progressiva de três categorias, a saber: infecção contraída pelo ato sexual: vai acontecer comigo?; relacionamentos estáveis: grupos de riscos ou proteção? e desconsideração das vulnerabilidades às IST: eu sei, mas não me importo!

\section{Infecção contraída pelo ato sexual: vai acontecer comigo?}

Conforme os depoimentos, algumas mulheres compreendem que as práticas sexuais desprotegidas geram impacto na saúde sexual e podem contribuir para ocorrência de infecções, pois se percebem como vulneráveis as IST, em virtude do comportamento sexual de risco, de não usar o preservativo. Inclusive foi referido por elas que a única forma de está imune às IST, é por meio da abstinência sexual:

Porque não gosto de fazer relação com camisinha. (...) Eu sei se qualquer coisa acontecer é por causa de mim mesmo porque eu não gosto. (E1).

Agora acho, que uma mulher seria imune a DST, só se ela não tivesse nenhum tipo de relação ou fosse virgem, essas coisas. (E2).

A minha vulnerabilidade é justamente por isso, porque eu sei a situação, sei o histórico do que se passou, mas eu continuo no mesmo caminho. (...) porque eu não me previno de jeito nenhum ai eu acho que tenho mais possibilidades de ter essas. (E5).

Algumas mulheres percebem a sua vulnerabilidade relacionada a vivências anteriores com IST, sendo que uma delas percebeu que tal condição é característica do seu próprio corpo, pois tem predisposição a contrair essas infecções: 
Porque eu já peguei, ai acho que posso pegar também de novo. (E1).

Acho, pelo o que eu passei com essa doença (...). (E3).

Eu acho que meu organismo esta adapto a pegar outras coisas. (E5).

As falas das mulheres elucidam que a maioria apresenta uma baixa percepção de vulnerabilidade, visto que para elas ser vulnerável é próprio daquelas que tem um estilo de vida sexual de promiscuidade, desregramento e comportamentos não aceitos moralmente, estando estas "protegidas" por não se enquadrarem nesses critérios que julgam centrais para serem vulneráveis às IST:

(...) se está só com aquela pessoa, não faz sexo com outras pessoas, eu acho assim né (...). (E3).

(...) porque a pessoa que sai com caras pega. (...) eu saio com outros homens, ai tenho capacidade de pega (...). (E4).

(...) se a mulher tiver relação com um, com outro e com outro, ai sim. (E5).

(...) só se for o caso assim, se a mulher tiver outros homens, ai é perigosos mermo pegar, mas eu só tenho esse que eu vivo (...). (E6).

As mulheres constroem a premissa de que o "outro" é o responsável pela contaminação. Para elas, a insegurança quanto ao comportamento do parceiro, o desconhecimento ou próprio conhecimento da situação sexual de saúde dele; descuido em relação a sua saúde e falta de higienização destes são fatores que as colocam em situação de vulnerabilidade. Desse modo, percebem no parceiro o potencial para contrair essas infecções:

(...) ai a gente foi fazer um exame de sangue ai deu que ele tinha herpes genital (...). Sim, por isso, sei lá. (E2).

Por que eu não sei a situação que ele esta, se ele tem alguma doença, se ele não tem. (...). (E3)

Eu tenho medo, sei lá, porque do jeito que hoje em dia está ninguém pode nem confiar. (E5).

Tem homens que é sujo, uns são limpos outros são sujos, da ate um ranço na pessoa. (E4).

(...) Não adianta só eu cuidar de mim, sem ele está cuidado dele (...). (E8).

\section{Relacionamentos estáveis: são grupos de riscos/ proteção?}

As percepções reveladas nos discursos das entrevistadas refletem que a vulnerabilidade às IST das mulheres em relacionamentos estáveis está ancorada a grupos de risco e proteção. Aquelas que se consideram como "grupos de riscos" são justamente as que percebem que possuir uma vida sexual ativa já é motivo suficiente para serem vulneráveis às IST, mesmo tendo uma relação estável:

Eu acho que tem, não sei por que, mas eu acho que tem, porque tem relação ali direto, e de alguma forma transmite, num sei, mesmo ela tendo uma relação estável, eu acho que tem. (E5).

Outra situação revelada entre aquelas que percebem o relacionamento estável como um grupo de risco para contrair IST está vinculado ao comportamento do "outro", no caso aqui o parceiro, como sendo o principal responsável por colocá-las em situação de vulnerabilidade, principalmente em virtude de infidelidade:

No caso ai é perigoso, ninguém sabe com quem ele fica né, ela num vai saber, e também ninguém vai acreditar também (,,,). (E3).

Eu acho que sim, por que a gente nunca sabe né, a gente às vezes conhece a pessoa né, mora dentro de casa com a pessoa e as vezes a gente não sabe a situação de saúde né (...). (E7).

Houve mulheres que realçaram os relacionamentos estáveis como grupo de risco pela naturalização existente das relações extraconjugais, cujos homens e mulheres não têm como fito uma relação construída com base em preceitos morais de compromisso, respeito e fidelidade.

A maioria dos homens e as mulheres também se relacionam com outras pessoas, apesar de ser junto. (E1).

Percebeu-se a baixa percepção de vulnerabilidade entre a maioria das mulheres, fator que torna o relacionamento estável um cenário crítico no contexto de vulnerabilidade às IST, pois, geralmente, não há adoção de comportamentos protetores. Para as depoentes, os relacionamentos estáveis promovem segurança às mulheres, "protegendo-as" de serem acometidas por IST, creditando na monogamia a garantia para a fidelidade do parceiro e a prevenção dessas infecções:

Na minha opinião, não tem não, porque está só com aquela pessoa, não faz sexo com outras pessoas, eu acho assim né, na minha opinião. (E3).

Ela só tem risco, se outro não brincar né, se o homem não gostar de namorar por fora, ai ela tem. Agora se ele for mesmo só com ela, acho que não tem não (...). (E4).

\section{Desconsideração das vulnerabilidades às IST: eu sei, mas não me importo!}

Ao adentrar no campo subjetivo das mulheres, percebeu-se uma estranheza revelada frente à problemática das vulnerabilidades 
às IST, visto que algumas consideram natural o relacionamento extraconjugal, seja do companheiro ou o próprio. Aponta-se também que apesar de já terem sido acometidas por algum tipo dessas infecções e serem conscientes que podem reincidir, se comportam com descuido, desconsiderando uma vida sexual segura:

Ele não sabe que eu tenho relações por fora. (...) quando eu vou atrás dum, que eu saio no meio do mundo atrás, já sabe que é atrás dessas coisas né. (E4).

Não me importei não, porque se tivesse me importado eu não tinha voltado pra ele de novo. (E6).

(...) porque eu sei que pode ocasionar dele transmitir pra mim, mas eu não me previno. (E8).

Ainda tiveram aquelas que pareceram imparciais a situação discutida, pois demonstraram não se importarem em contrair novamente uma IST. São conhecedoras de que o parceiro é portador de doença sexual, mesmo assim mantinham relação desprotegida, inclusive houve aquelas que se abstinham do ato sexual com o parceiro, não por ele estar com uma IST, mas pela impossibilidade relacionada a desconfortos deste:

Sinceramente não me preocupa (...). (E7).

(...) Deu que ele tinha herpes genital (...). Porem entre agente não existe o uso do preservativo. Quando ele estava com a feridinha não tive relações com ele, não tem como ter (...). (E2).

A confiança no parceiro é um elemento elencado por elas, que contribui para que essas mulheres não considerem sua vulnerabilidade às IST. A convicção da fidelidade do parceiro aumenta as probabilidades de recorrências dessas infecções em suas vidas, haja vista que elas desconsiderem totalmente a adoção de práticas sexuais seguras. Entre as mulheres participantes, a palavra confiança se reveste de outro sentido que não necessariamente seria acreditar na fidelidade, mas a crença na prevenção do parceiro em caso de relações extraconjugais:

É altamente fiel tenho certeza disso (...) e principalmente, por ele ter medo por já estar passando por isso ele não ia sem o preservativo (...). (E2).

(...) é claro que eu confio muito nele, eu confio demais

(...). Eu acho que se ele tivesse tido alguma coisa ele teria me dito. Ele sempre me fala tudo. (E5).

(...) acho que é porque eu confio demais nele, se eu tiver pegado dele foi de muito tempo atrás, já vem guardado (...). (E7).

Além das situações referidas, as falas revelam que a desconsideração da vulnerabilidade também está relacionada a atitudes do parceiro que geralmente não se percebem como vulneráveis às IST, logo são irredutíveis quando o assunto é relação sexual com proteção:

(...) fiz relação com ele sem saber que ele tinha doença. (E3).

Sei não, conheço não. Ele disse que pegou quando era rapaz e deu foi trabalho para ficar bom (...). (E4).

Não. Não sei. (...). (E8).

\section{DISCUSSÃO}

A partir das informações obtidas, buscou-se lançar um olhar para as vulnerabilidades nelas envolvidas, partindo do pressuposto da compreensão de vulnerabilidade como a possibilidade de exposição das pessoas ao adoecimento resultante não somente de um conjunto de aspectos individuais, mas de fatores coletivos e contextuais que acarretam aos indivíduos maior suscetibilidade frente à disponibilidade de recursos para se protegerem..$^{9,11-15}$

Os elementos identificados favorecem a prática sexual insegura, sem amadurecimento psicoafetivo e responsabilidade, deixando-as vulneráveis. Em outro estudo foram encontrados resultados parecidos ao identificar que as mulheres percebem a importância da relação sexual com proteção e a vulnerabilidade relacionada a esta causa, no entanto por diversos motivos não utilizam, sendo que na maioria das vezes porque não querem. ${ }^{16}$

O que difere dos resultados encontrados em um estudo, no qual muitas mulheres apesar de reconhecerem que o uso do preservativo, é uma das principais medidas para prevenção das IST/HIV e de se perceberem como praticantes de comportamento de risco, não admitem que possam chegar a contrair essas infecções. ${ }^{17}$

A autopercepção de vulnerabilidade esboçada pelas mulheres remete ao seguinte questionamento: "Por que não adotar prática sexual segura, se existe a consciência das possibilidades de uma recontaminação?". Essas e outras indagações prescindem de respostas e reflexões acerca disso, que pode facilitar a abertura de um espaço para uma abordagem na saúde a qual aproxime os profissionais com as mulheres, a fim de que seja possível compreender os arranjos imbricados ao problema para então, programar estratégias resolutivas, imantada pelas vulnerabilidades vivenciadas.

A compreensão deve ser despertada para questões mais amplas no sentido "integral" que possam repensar e reconhecer os processos que irrompe a vulnerabilidade, não somente em seu caráter individual, mas também no social que é um de seus elementos como processos contínuos de forças que desenham os caminhos pelos quais o indivíduo-social é reconhecido na cena social. Os elementos essenciais da vulnerabilidade em saúde são diversos e múltiplos e não são compreendidos como dimensões, haja vista que cada um tem suas características e conceitos, porém interconectados, ou seja, só existem na presença do outro, ao mesmo tempo em que por diversas vezes suas características podem se confundir. ${ }^{9}$ 
Acredita-se então que, para compreender a vulnerabilidade, é preciso desdobrar de forma crítica e reflexiva os desafios e tensões envoltos na realidade das pessoas e não somente percebe-la como mero exercício intelectual, no sentido de se efetivar a perspectiva de políticas públicas de saúde proativa, preventiva e protetiva.

A baixa percepção de vulnerabilidade para uma IST geralmente está relacionada à sensação de proteção, principalmente quando as mulheres são casadas ou têm parceiro fixo e estável, assim como quando não possuem mais a possibilidade de engravidar. ${ }^{15}$ Portanto, indivíduos que não se sentem vulneráveis a uma doença não costumam aceitar as medidas preventivas recomendadas.

A percepção da vulnerabilidade está ligada à confiança no parceiro, na situação em que este se encontra e ao uso do preservativo na relação sexual. Grande parte das mulheres continua não se percebendo vulnerável às IST/AIDS ou tem consciência da importância e não se protege. ${ }^{18}$

Essa percepção entre a maioria das mulheres foi justificada pela crença de estarem engajadas em relações afetivo-sexuais estáveis, nas quais pressupunham a exclusividade sexual mútua. Elas sustentaram que esse cuidado preventivo era prescindível em suas relações, uma vez que tinham um único parceiro e acreditavam que este não tivesse outra parceira. Suas concepções de vulnerabilidade estavam, em grande parte, vinculadas à multiplicidade de parceria, passível de acontecer quando não há compromisso de exclusividade ou quando este compromisso não é mantido. ${ }^{10}$

Corroborando com esses achados, foi identificado em um estudo que às representações de vulnerabilidade para as mulheres está relacionada a determinadas limitações e particularidades, presente no "outro", parecendo que elas mesmas estariam excluidas de tais situações e possibilidade. Outro fator importante é o julgamento de que as pessoas vulneráveis possuem um perfil determinado, já que na concepção delas quem estaria em risco seriam as mulheres com múltiplos parceiros que não se protegem usando o preservativo. ${ }^{19}$

Afunilando olhares para esse panorama, apreende-se uma teia regada por situações de vulnerabilidades a qual as mulheres estão envolvidas, tendo em vista que não são conscientes e sensibilizadas com concretude quanto à vulnerabilidade a qual estão expostas nas relações sexuais, fazendo com que elas assumam um comportamento despreocupado ou de não percepção frente ao risco e à prevenção de IST.

A saúde sexual é parte fundamental da avaliação geral de saúde de qualquer pessoa. Desse modo, conhecer a história sexual e identificar as vulnerabilidades é fundamental para uma abordagem centrada na pessoa, permitindo assim conhecê-la como um todo. Essa investigação deve ser estruturada para identificar os fatores de vulnerabilidade relacionados à saúde sexual, reconhecendo práticas e comportamentos sexuais e também oportunidades para intervenções breves de mudança comportamental. ${ }^{20}$

Nesse contexto, faz-se importante ampliar ações englobando programas de promoção à saúde que sejam cada vez mais eficazes e resolutivos com o desafio e a obrigação moral e ética de torná-las acessíveis a todos e, sobretudo, para os segmentos especialmente vulneráveis como é o caso das mulheres. Há que se pensar em estratégias de orientação sexual que dialoguem com as realidades de vida das mulheres, atentando para as relações dos elementos sujeito e social, as quais tencionam a situações de precariedade e empoderamento, e em conjunto assumem várias nuances que potencializam ou fragilizam os processos de vulnerabilidade em saúde. ${ }^{16}$

Mulheres que vivem casadas ou em união estável, em geral, possuem baixa percepção de vulnerabilidade por creditar nesses laços afetivos fator de proteção e em decorrência não adotam um comportamento sexual seguro, colocando-as em situações de vulnerabilidade em relação às IST. ${ }^{21,22}$ Portanto, esse sentimento de proteção limita a mulher a questionar-se sobre sua vulnerabilidade e, se acometidas por essas infecções, favorece a falta de diagnóstico precoce, impede que o tratamento seja iniciado, contribuindo para as complicações advindas do agravo além de perpetuar a transmissão. ${ }^{10}$

Acredita-se ser fundamental valorizar, promover e incentivar o autoconhecimento que implica conhecer a si próprio, os valores, os sentimentos, o modo de ver e viver a vida e as relações com os outros para que seja possível a construção de um envolvimento afetivo saudável que contribua para o crescimento pessoal, superação de dificuldades e fortalecimento da autoestima. ${ }^{23}$

Por tantas outras mulheres terem as mesmas percepções, considera-se que as atividades de promoção de saúde sexual devem ser voltadas para o casal, a partir de estratégias efetivas e viáveis que enfatizem as diferentes vulnerabilidades, alertando sobre os riscos de infecção e promovendo mudanças nas atitudes de ambos, como o respeito e proteção pela pessoa que ama ou que se relaciona.

Os resultados revelaram elementos importantes das caraterísticas, comportamentos e contextos que conduz as mulheres a uma desconsideração das vulnerabilidades, situação que limita a iniciativa delas a se prevenirem das IST. Tais informações são indicativas de um cenário inquietante, ao passo que as mulheres não incorporam em sua vida atitudes protetoras de forma regular e consistente, mostrando a vulnerabilidade no que tange ao seu comportamento sexual e a outros determinantes sociais. Outros estudos mostraram as mesmas evidências de que as mulheres apresentam consciência do risco, mas não adotam medidas preventivas. ${ }^{18,24}$

Resultado similar foi encontrado em uma pesquisa na qual a vulnerabilidade feminina também está associada a eventos extraconjugais, principalmente por parte dos homens, sendo que as mulheres sabem destes eventos de infidelidade e os aceitam por considerar como uma necessidade do sexo masculino e não efetivam a cobrança do uso do preservativo, contribuindo, assim, para a aquisição de uma IST. ${ }^{25}$

Pesquisas apontam que uma das motivações para as mulheres não se protegerem diz respeito à confiança no parceiro, já que a convivência e a intimidade construídas na relação parecem afastar o risco de contágio para IST. A expressão confiança é interpretada pelas mulheres como a atitude preventiva do marido em seus possíveis relacionamentos extraconjugal. Portanto, as mulheres acabam por desconsiderar sua vulnerabilidade ao depositar segurança em seus relacionamentos se expondo muitas vezes a riscos, se não houver fidelidade por parte dos seus parceiros. ${ }^{26,27}$ 
Pesquisa realizada com mulheres em outros estados do Nordeste demostrou que a adoção do preservativo depende da concordância masculina, o que é um percalço à prevenção, já que eles não gostam de métodos de barreira por acreditarem que estes interferem no prazer sexual. ${ }^{28}$ Nesse contexto, acredita-se que a inclusão do homem em estratégias preventivas se constitui um ponto de mudança positiva ao enfrentamento dessas doenças, já que seu comportamento atinge diretamente a companheira. ${ }^{28}$

Entre mulheres afro-americanas o uso consistente do preservativo foi predito pelas seguintes variáveis: ter maior percepção da relevância da negociação do preservativo, menor medo de negociar o uso do preservativo e ter conversado com parceiros sexuais sobre prevenção. ${ }^{29}$

A mulher faz parte de um dos grupos mais vulnerável às IST, tendo como principal fator o papel cultural e social ao qual ela é submetida ao longo dos anos, de exclusão da tomada de decisões tanto na sua vida pública, como na pessoal. Em comparação ao sexo masculino, tem menor autonomia em sua vida sexual e, consequentemente, menos poder de decisão acerca do sexo com proteção, impactando cada vez mais em situações de vulnerabilidades as IST. ${ }^{30}$

Tais informações merecem reflexão sobre o que vem sendo discutido sobre vulnerabilidade para que as pessoas, em especial as mulheres, percebam situações que podem colocá-las como vulneráveis, ponderando sobre suas vivências e práticas. Enfatiza-se também que quanto menos vulnerável se sentem as pessoas, menos se cuidam para evitar determinados malefícios. ${ }^{19}$ Nessa perspectiva, é indispensável fazer com que as mulheres que não tenham noção do risco e nem poder de mudar o comportamento do parceiro compreendam que o risco também pertence a elas. ${ }^{31}$

Compreende-se que, nos processos de vulnerabilidade em saúde, a relação de poder entre o sujeito e o social é um campo aberto de respostas, reações, resultados e possíveis invenções que podem resultar em condições de precariedade e empoderamento. As condições de precariedade envolvem situações de diferentes formas que representam uma esfera de iniquidades sociais e, assim, acabam por reforçar as situações de Vulnerabilidade em Saúde. De outro modo, existe a possibilidade de transformar esses processos por meio da vivência do empoderamento, uma vez que o sujeito pode obter meios para enfrentar e minimizar as situações de Vulnerabilidade em Saúde. ${ }^{16}$

A ideia embutida, nessa perspectiva, é a de aprofundamento da democracia do ponto de vista individual e social em que as pessoas são protagonistas de suas vidas e projetos. No processo de empoderamento, as mulheres reconhecem que podem desenvolver um senso de si capaz de se autodefender, conquistar, avançar e superar não somente as adversidades, mas também obstáculos humanos comuns. É o ato de se apossar desses recursos internos que as tornam sujeitos ativos, autônomos e emancipados do processo de suas existências, seja no exercício de uma conjugalidade igualitária, a prevenção ou tratamento de uma doença, a denúncia por maus tratos, a administração da sua sexualidade. ${ }^{32}$ No entanto, não basta que isso fique somente no plano individual, pois o empoderar-se é relacional e depende das interações com o ambiente em que as mulheres estão circunscritas. ${ }^{32}$

\section{CONCLUSÕES}

A pesquisa permitiu constatar a baixa percepção das mulheres em relação às vulnerabilidades às IST, situação que as levam a se sentirem protegidas e limitam a sua consideração de vulnerabilidade para realizarem ações concretas de prevenção, potencializando a condição de vulnerabilização. Elas acreditam que a possibilidade de adquirir IST está vinculada a comportamentos considerados desviantes, sendo provável apenas na vida de quem não vivencia um relacionamento estável, perpetuando ideias sobre tais doenças que já deveriam ter sido descontruídas. ${ }^{19}$

Desse modo, o principal desafio é traduzir as soluções para a superação dos diferentes contextos de vulnerabilidade das mulheres às IST, a partir da elaboração de políticas efetivas e ações concretas que assegurem o acesso aos programas de promoção e prevenção, disponíveis no sistema de saúde, com garantia de uma assistência holística e integral para a saúde da mulher.

É necessário reorientar os serviços da APS a fim de que os profissionais e gestores percebam que questões políticas, sociais, culturas e econômicas permeiam as situações de vulnerabilidade a que as mulheres estão expostas e assim possibilitar que estas sejam protagonistas de sua saúde, o que fortalecerá políticas públicas inerentes a suas realidades e vulnerabilidades.

Por fim, cabe destacar como limitações desse estudo o fato de que não se adentrou nos aspectos relacionados à situação programática da vulnerabilidade, fator que fundamentaria ainda mais os achados encontrados, de forma a contribuir com as lacunas existentes na APS, pois acredita-se que para os serviços de saúde conseguir oferecer aquilo que a comunidade precisa, são necessárias avaliações continuas dos processos de trabalhos e identificação de estratégias que garantam os princípios e diretrizes do Sistema Único de Saúde (SUS).

Contudo, este estudo não esgota a compreensão da vulnerabilidade de mulheres às IST, dada a complexidade do assunto, logo se propõe a aplicação de pesquisas que tragam soluções para os equívocos encontrados no que diz respeito às percepções das mulheres quanto a sua vulnerabilidade às IST. Além disso, julga-se necessário o desenvolvimento de outros estudos, que possam investigar mais conceitos e subconceitos e as relações estabelecidas pelas mulheres que envolvam os processos de vulnerabilidade em saúde.

\section{AGRADECIMENTOS}

A Rede Nordeste de Formação em Saúde da Família (RENASF), a Universidade Estadual Vale do Acaraú e seus docentes, agradecemos pela contribuição com o desenvolvimento dessa pesquisa.

\section{CONTRIBUIÇÕES DOS AUTORES}

Desenho do estudo. Aquisição análise de dados e interpretação dos resultados. Redação e revisão crítica do manuscrito. Aprovação da versão final do artigo. Responsabilidade por todos os aspectos do conteúdo e a integridade do artigo publicado. Samy Loraynn Oliveira Moura. 
Análise de dados e interpretação dos resultados. Redação e revisão crítica do manuscrito. Aprovação da versão final do artigo. Responsabilidade por todos os aspectos do conteúdo e a integridade do artigo publicado. Andréa Carvalho Araújo Moreira. Ana Karina Bezerra Pinheiro. Cibelly Aliny Siqueira Lima Freitas. Maria Adelane Monteiro da Silva

\section{EDITOR ASSOCIADO}

\section{Stela Maris de Mello Padoin}

\section{REFERÊNCIAS}

1. World Health Organization. Sexually Transmitted Infections (STIs). Geneva: WHO; 2015.

2. Pinto VM, Basso CR, Barros CRDS, Gutierrez EB. Fatores associados às infecções sexualmente transmissíveis: inquérito populacional no município de São Paulo, Brasil. Cien Saude Colet.2018;23(7):2423-32. http://dx.doi. org/10.1590/1413-81232018237.20602016. PMid:30020394.

3. World Health Organization. Global incidence and prevalence of selected curable sexually transmitted infections. Geneva: WHO; 2008.

4. Ministério da Saúde (BR). Secretaria de Vigilância em Saúde. Departamento de DST, Aids e Hepatites Virais. Protocolo clínico e diretrizes terapêuticas para atenção integral às pessoas com infecções sexualmente transmissiveis. Brasília: Ministério da Saúde; 2015.120 p.

5. Nascimento VB, Martins NVN, Ciosak SI, Nichiata LYI, Oliveira JSS, Bezerra LO et al.Vulnerabilidades de mulheres quilombolas no interior da Amazônia às infecções sexualmente transmissíveis: um relato de experiência. IJHEInterdisciplinary Journal of Health Education. 2017;2(1):68-73. http://dx.doi. org/10.4322/ijhe.2016.029.

6. Costa FMD, Mendes ACF, Maria DC, Santos JAD, Costa GMD, Carneiro JA. A percepção feminina quanto à vulnerabilidade de se contrair DST/ AIDS. Rev Univ Vale Rio Verde. 2014;12(2). http://dx.doi.org/10.5892/ruvrd. v12i2.1744.

7. Rodrigues LSA, Paiva MS, Oliveira JF, Nóbrega SM. Vulnerability of women in common-law marriage to becoming infected with HIV/AIDS: a study of social representations. Rev Esc Enferm USP.2012 abr;46(2):349-55. http:// dx.doi.org/10.1590/S0080-62342012000200012. PMid:22576538.

8. Ayres JRCM. Vulnerabilidade, direitos humanos e cuidado: aportes conceituais. In: Barros S, Campos PFS, Fernandes JJS, organizadores. Atenção à saúde de populações vulneráveis. Barueri: Manole; 2014 .

9. Florêncio RS. Vulnerabilidade em saúde: uma clarificação conceitual [tese]. Fortaleza: Universidade Estadual do Ceará; 2018.

10. Carmo ME, Guizardi FL. O conceito de vulnerabilidade e seus sentidos para as políticas públicas de saúde e assistência social. Cad Saude Publica. 2018;34(3):34. http://dx.doi.org/10.1590/0102-311x00101417.

11. Ministério da Saúde (BR). Secretaria de Vigilância em Saúde. Departamento de Informática do SUS. Sistema de Informação de Agravos de Notificação. Brasilia: Ministério da Saúde;2018 [citado 2019 set 15). Disponível em: http:// www.saude.gov.br/sinan_net

12. Polit DF, Beck CT, Hungler BO. Fundamentos de pesquisa em Enfermagem: métodos, avaliação e utilização. $5^{a}$ ed. Porto Alegre: Artes Médicas; 2004.

13. Bardin L. Análise de conteúdo. Pinheiro LA, Tradução. São Paulo: Edições 70; 2016.

14. Resolução № 466, de 12 de dezembro de 2012 (BR). Diário Oficial da União, Brasília (DF), 13 jun 2013: Seção 1: 59.

15. Meneses MO, Vieira BDG, Queiroz ABA, Alves VH, Rodrigues DP, Silva JCSD. O perfil do comportamento sexual de risco de mulheres soropositivas para sifilis. Rev enferm UFPE on line. [Internet]. 2017; [citado 2019 ago 20];11(4):1584-94. Disponível em: https://periodicos.ufpe.br/revistas/ revistaenfermagem/article/viewFile/15226/17989

16. Silva $\mathrm{BC}$, Oliveira $\mathrm{MC}$. Percepções sobre sexualidade em relação às doenças sexualmente transmissíveis de pessoas adultas na atenção básica. Rev Gespevida [Internet]. 2015; [citado 2019 ago 20];1(1):88-99 Disponível em:http://www.icepsc.com.br/ojs/index.php/gepesvida/article/ view/68/42

17. Rufino ÉC, Andrade SSC, Leadebal ODCP, Brito KKG, Silva FMC, Santos SH. Conhecimento de mulheres sobre IST/AIDS: intervindo com educação em saúde. Ciênc cuid saúde. 2016;15(2):304-12.

18. Lobo LMGA, Almeida MM, SantosTS, Moraes WBS, Freitas DES, Oliveira FBM. Vulnerabilidade feminina para infecções sexualmente transmissíveis durante visita íntima. Rev Eletrônica Acervo Saúde. 2019; 11 (8): http:// dx.doi.org/10.25248/reas.e653.2019.

19. Costa SP, Silva TB, Rocha TA, Guisande TCCA, Cardoso AM, Gomes $\mathrm{JL}$ et al. Saberes e representações de vulnerabilidade para DST/HIV/ AIDS por jovens universitárias. Id on Line Rev M Psic. 2016;10(31):25-42. https://doi.org/10.14295/idonline.v10i31.483.

20. Clutterbuck DJ, Asboe D, Barber T, Emerson C, Field N, Gibson S et al United Kingdom national guideline on the sexual health care of men who have sex with men. Int J STD AIDS. 2018;1(1):956462417746897. PMid:29334885.

21. Lima IMB, Oliveira AEC, Andrade JM, Coêlho HFC, Lima KS. Modelo de decisão sobre o uso de preservativos: uma regressão logística multinomial. Tempus Actas de Saúde Coletiva. 2016;10(2):67-80. http:// dx.doi.org/10.18569/tempus.v10i2.1649.

22. Pinto VM, Basso CR, Barros CRDS, Gutierrez EB. Fatores associados às infecções sexualmente transmissíveis: inquérito populacional no município de São Paulo, Brasil. Cien Saude Col. 2018;23(7):2423-32. https://doi. org/10.1590/1413-81232018237.20602016.

23. Ministério da Saúde (BR). Secretaria de Atenção à Saúde. Departamento de Atenção Básica. Saúde sexual e saúde reprodutiva. Brasília: Ministério da Saúde; 2013. (Cadernos de Atenção Básica, n. 26).

24. Costa ACPJ, Lins AG, Araújo MFM, Araújo TM, Gubert FA, Vieira NFC. Vulnerabilidade de adolescentes escolares às DST/HIV, em Imperatriz - Maranhão. Rev Gaúcha Enferm. 2013;34(3):179-86. http://dx.doi. org/10.1590/S1983-14472013000300023.

25. Figueiredo LG, Silva RAR, Silva ITS, Souza KGS, Silva FFA. Percepção de mulheres casadas sobre o risco de infecção pelo HIV e o comportamento preventivo. Rev Enferm UERJ [Internet]. 2013; [citado 2019 set 15];21(2, N esp.):805-11. Disponível em: http://www.facenf.uerj.br/v21esp2/v21e2a18. pdf

26. Garcia S, Berquó E, Lopes F, Lima LP, Souza FM. Práticas sexuais e vulnerabilidades ao HIV/AIDS no contexto brasileiro: considerações sobre as desigualdades de gênero, raça e geração no enfrentamento da epidemia. Demografia em Debate [Internet]. 2015; [citado 2019 set 15];2:417-48. Disponível em: http://www.abep.org.br/ abeporgb/publicacoes/index. php/ebook/article/viewFile/59/5

27. Francisco MTR, Fonte VRF, Pinheiro CDP, Silva MES, Spindola T, Lima DVM. O uso do preservativo entre os participantes do Carnaval-perspectiva de gênero. Esc Anna Nery. 2016;20(1):106-13.

28. Andrade SSC, Zaccara AAL, Leite KNS, Brito KKG, Soares MJGO, Costa MML et al. Conhecimento, atitude e prática de mulheres de um aglomerado subnormal sobre preservativos. Rev Esc Enferm USP. 2015 jun;49(3):364-71. http://dx.doi.org/10.1590/S0080-623420150000300002. PMid:26107695.

29. Crosby RA, DiClemente RJ, Salazar LF, Wingood GM, McDermott-Sales $\mathrm{J}$, Young AM et al. Predictors of consistent condom use among young African American women. AIDS Behav. 2013;17(3):865-71. http://dx.doi. org/10.1007/s10461-011-9998-7. PMid:21796442.

30. Hankivsky $\mathrm{O}$. Women's health, men's health, and gender and health: Implications of intersectionality. Soc Sci Med.2012;74(11):1712-20. http:// dx.doi.org/10.1016/j.socscimed.2011.11.029. PMid:22361090.

31. Silva CM, Vargens OMC. Aids como doença do outro: uma análise da vulnerabilidade feminina. Revista de Pesquisa Cuidado é Fundamental [Online]. [Internet]. 2015;[citado 2019 set 17];7(4):3125-34. Disponível em: https://www.redalyc.org/pdf/5057/505750948001.pdf

32. Von Muhlen BK, Saldanha M, Strey MN. Mulheres e o HIV/AIDS: intersecções entre gênero, feminismo, psicologia e saúde pública. Revista Colombiana de Psicologia. 2014;23(2):3.

\footnotetext{
a Artigo extraído da dissertação de mestrado em Saúde da Familia, "vivências de vulnerabilidades de mulheres as infecções sexualmente transmissíveis na atenção primária à saúde." Mestrado Profissional em Saúde da Família da Rede Nordeste de Formação em Saúde da Família (RENASF). Autoria de Samy Loraynn Oliveira Moura. Orientadora: Maria Adelane Monteiro da Silva. Sobral. 2019, 107p.
} 